\title{
El rol de la ingeniería y la investigación en ingeniería en el proceso de licenciamiento ambiental, estudio de caso en Chile $^{1}$
}

\author{
The role of Engineering and Engineering Science in Environmental Licensing, Case Study: Chile
}

\author{
Ignacio Toro Labbé ${ }^{(1)}$ \\ (1) M.Sc. en Ciencias de la Ingeniería, Pontificia Universidad Católica de Chile. Exdirector Ejecutivo del Servicio de Evaluación Am- \\ biental de Chile (SEA) y Exdirector Ejecutivo de la Comisión Nacional del Medio Ambiente (CONAMA). Gerente Área Ambiental \\ Pares\&Alvarez, Santiago de Chile, Chile. ignaciotoro2015@gmail.com
}

Recibido 26 de octubre de 2015. Modificado 7 de diciembre de 2015. Aprobado 15 de diciembre de 2015.

DOI: http//:dx.doi.org/10.16924/riua.v0i43.904

\begin{abstract}
Palabras clave
Chile, evaluación ambiental, ingeniería, investigación, licenciamiento ambiental, normativas.

\section{Resumen}

En este artículo se analiza el rol de la ingeniería y la investigación en el proceso de licenciamiento ambiental a la luz del cambio institucional realizado en Chile a partir de 2010: la creación del Ministerio de Ambiente y el Servicio de Evaluación Ambiental. Para ello, se mostrarán los desafíos existentes a la hora de implementar esa nueva institucionalidad, las oportunidades detectadas y el trabajo realizado para hacer frente a esos cambios. Finalmente, se presentarán los resultados obtenidos hasta este momento teniendo como modelo el proyecto Punta Alcalde.
\end{abstract}

\section{Key words}

Chile, Engineering, Engineering Science, Environmental Assessment, Environmental Licensing, Regulations.

\begin{abstract}
In this paper, we analyze the role of engineering and research in the environmental licensing process in the light of institutional changes made in Chile since 2010: the creation of the Ministry of Environment and the Environmental Assessment Service. To do this, we will show the challenges posed by these new institutions, the opportunities identified and the work undertaken to address those changes. Finally, the results will be presented taking the Punta Alcalde project as a model.
\end{abstract}

\section{INTRODUCCIÓN}

El estudio realizado por MorrisonSaunders y Sadler (2010) mostraba que la opinión generalizada de expertos en evaluación de impacto, respecto a los sistemas de evaluación de impacto ambiental, era que las opiniones de políticos así como la percepción comunitaria tienen demasiada influencia sobre la suerte de los proyectos que se someten al sistema, y que los análisis científicos tienen influencia menor en ello. A pesar de lo anterior, el mismo estudio muestra que entre los entrevistados hay acuerdo en que un proceso de evaluación de impacto ambiental exitoso requiere un reporte científico confiable así como conocimiento objetivo y análisis realizados por especialistas calificados; ¿cómo se compatibiliza lo anterior? El mismo estudio muestra que la evaluación de impacto ambiental contiene dos aspectos diferentes, a saber: i) el primero, que podemos denominar "la ciencia de evaluación de impacto", tiene relación con la obtención y el análisis de información necesaria para una toma de decisión informada y ii) el segundo aspecto, que podemos denominar "el arte de evaluación de impacto", referido a la toma de decisión respecto a los proyectos y que considera información científica y otros aspectos como contexto social y político.

\footnotetext{
1 Una versión preliminar de este artículo fue presentada por Ignacio Toro en el foro "El rol de la ingeniería y de la investigación en ingeniería en el proceso de licenciamiento ambiental”, realizado en la Universidad de los Andes el 26 de octubre de 2015.
} 


\section{Contexto Normativo Chileno}

Durante 2010 se aprobó en Chile la Ley 20.417, que introdujo modificaciones sustantivas a la institucionalidad ambiental chilena y al procedimiento de evaluación de impacto ambiental contenido en la Ley General de Bases del Medio Ambiente (Ley 19.300).

Dentro de los aspectos relevantes, relacionados con el tema en cuestión, estuvo el término de la Comisión Nacional de Medio Ambiente (CONAMA), que hasta ese entonces fue el órgano colegiado responsable del desarrollo normativo ambiental, del seguimiento del cumplimiento de los compromisos internacionales así como de la evaluación ambiental de los proyectos de inversión. En su reemplazo, se estableció una estructura orgánica que separó competencias y creó organismos especializados. Por una parte, se dotó al Estado de un Ministerio de Medio Ambiente (responsable del desarrollo de políticas y legislación ambiental, así como el seguimiento de los compromisos internacionales asumidos. En segundo lugar, se creó el Servicio de Evaluación Ambiental, responsable de la evaluación ambiental de proyectos. Por último, se creó una Superintendencia de Medio Ambiente, responsable de la fiscalización ambiental así como de la sanción de infracciones a normas y permisos. Luego, se dictó la Ley 20.600 que creó en el país los Tribunales Ambientales, tribunales especializados, de composición mixta, dedicados a conocer de los recursos judiciales respecto a temáticas ambientales.

Respecto a la evaluación ambiental de proyectos, nos parece destacable lo siguiente:

1. Crea un Servicio Público descentralizado ("Servicio de Evaluación Ambiental” - SEA) responsable de los aspectos técnicos de la evaluación ambiental con facultades para, entre otras cosas, generar Guías metodológicas que mejoren y acoten la discrecionalidad

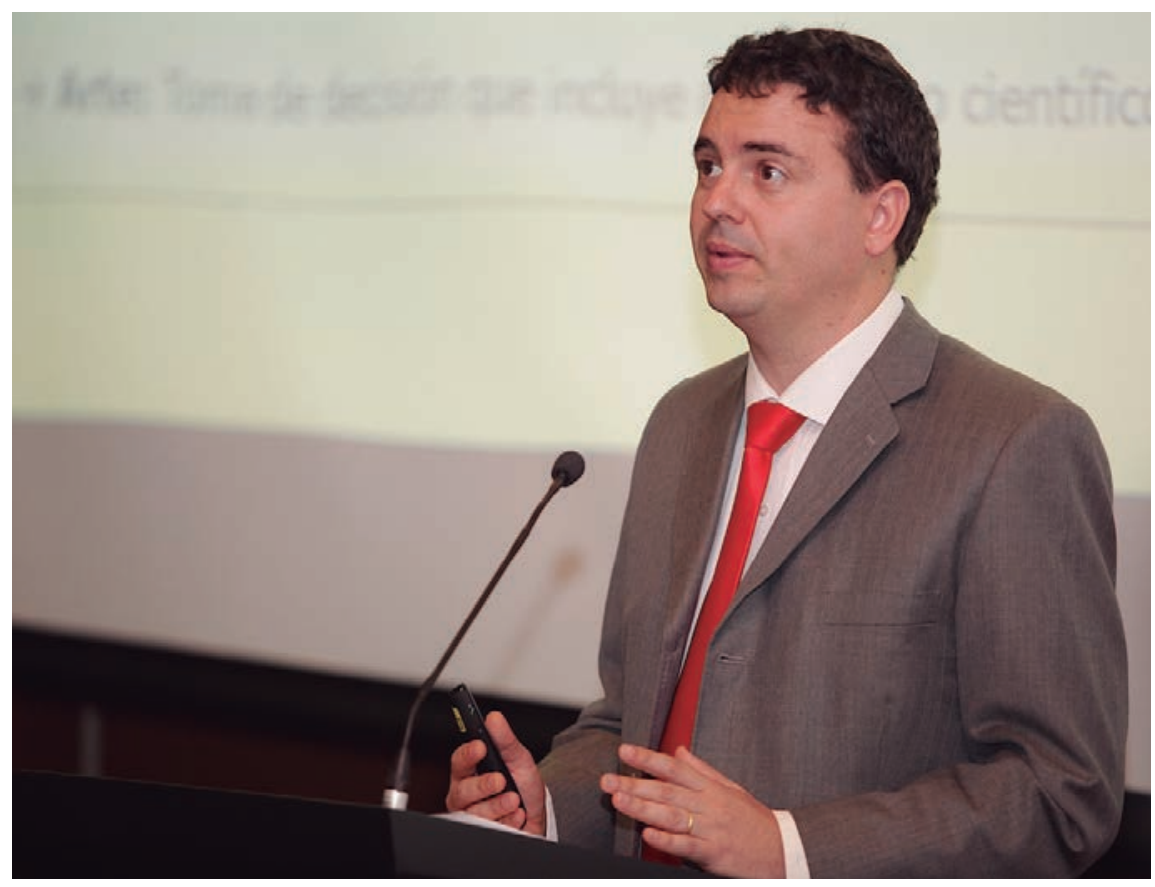

Ignacio Toro Labbé. Fuente: Archivo Particular, Universidad de los Andes

durante la evaluación de impacto ambiental.

2. Crea un Órgano Colegiado (el "Comité Técnico") compuesto por los órganos de la administración del Estado con competencias ambientales, responsable de los aspectos técnicos de la evaluación ambiental.

3. Crea un Órgano Colegiado (la “Comisión de Evaluación”), de integración técnico-política, responsable de calificar los proyectos ambientales regionales.

4. Genera la obligación al SEA de generar, de acuerdo a los antecedentes recabados durante la evaluación, una recomendación de aprobación o rechazo del proyecto a la Comisión de Evaluación, debiendo esta última considerarla.

5. Una vez calificada una Declaración de Impacto Ambiental o un Estudio de Impacto Ambiental, existen instancias recursivas. En el caso de los Estudios de Impacto Ambiental, tanto la ciudadanía como el titular del proyecto siempre pueden reclamar a un Comité de Ministros y este Comité, para resolver la reclamación, puede requerir información técnica adicional e independiente que le permita dirimir el conflicto asociado al proyecto.

De esta manera, la nueva institucionalidad chilena va en línea con reconocer que existen dos etapas diferenciadas durante la evaluación ambiental. La primera, una etapa asociada a levantar y analizar información técnica, que concluye con una recomendación de aprobación o rechazo; y, una segunda etapa en la que se adopta la decisión de aprobación o rechazo del proyecto propiamente tal, que si bien debe observar la recomendación técnica del SEA, puede verse modificada justificadamente por otros factores.

\section{Desafíos EXISTENTES AL MOMENTO DE INSTAURACIÓN DE LA NUEVA INSTITUCIONALIDAD}

En Chile existe un sistema de evaluación de impacto integrado, es decir en una sede única se evalúan los efectos sobre los recursos naturales, la salud de 
la población y la evaluación de impacto social.

El proceso de licenciamiento puede realizarse a través de una Declaración de Impacto Ambiental (DIA) en caso de que el proyecto no genere impactos significativos, o a través de un Estudio de Impacto Ambiental (EIA) en caso de que el proyecto genere impactos significativos.

Los proyectos sometidos a evaluación a través de una DIA son rechazados únicamente si no cumplen con la normativa ambiental vigente (lo que ocurre en contadas ocasiones) o porque generan impactos significativos que ameritarían que el proyecto se someta vía EIA. Los EIA, por su parte, se rechazan si no cumplen con las normas ambientales (lo que ocurre muy pocas veces) o porque los impactos significativos no se mitigan, compensan o reparan de manera adecuada.

En el caso de las DIA, el principal desafío en la gestión ambiental institucional es lograr calificar los proyectos dentro de los plazos legales (60 días ampliables a 90 días) ${ }^{1}$. Considerando que sólo hay que verificar que no exista incumplimiento legal y que no se generen impactos significativos, parecen plazos más que suficientes. Sin perjuicio de lo anterior, al año 2009, el 73\% de los proyectos se calificaba fuera de plazo.

En el caso de los EIA, el desafío era mayor. Esto por cuanto la reglamentación ambiental previa a la reforma era muy poco clara en cuanto a los requisitos mínimos que cada EIA debía contener para someterse a evaluación ambiental. Tampoco existían guías de qué modelos utilizar o cómo predecir el comportamiento del medio ambiente. Mucho menos criterios para determinar si un proyecto generaba o no impactos significativos ni cómo mitigarlos.

Junto a lo anterior, estaba el desafío de zanjar o delimitar las competencias de los distintos órganos de la administración del estado con

1 Cabe señalar que en el procedimiento de evaluación de impacto ambiental todos los plazos se refieren a días hábiles, es decir, contados de lunes a viernes exceptuando festivos. competencias ambientales y mejorar los procesos de participación ciudadana.

En resumen, y sobre todo con respecto a la evaluación ambiental de proyectos más complejos que requieren de un EIA, se requería la incorporación de la ciencia y de la ingeniería para poder hacerse cargo de los desafíos y mejorar el desempeño ambiental del sistema de evaluación.

\section{OPORTUNIDADES DETECTADAS Y TRABAJO DESARROLLADO}

Con la nueva institucionalidad, que dotó de un carácter eminentemente técnico al Servicio de Evaluación Ambiental y permitió diferenciar en forma más clara una etapa técnica de análisis y otra etapa política de toma de decisión, se generó la oportunidad real de hacerse cargo de las falencias indicadas anteriormente para mejorar el desempeño ambiental. Esta oportunidad se abordó orgánica y normativamente mediante los siguientes instrumentos:

1. Generación de un nuevo Reglamento para la evaluación de Impacto Ambiental: Se trabajó en un nuevo reglamento de evaluación de impacto ambiental que introdujo varias modificaciones sustantivas a la forma cómo se venía realizando la evaluación. Las principales modificaciones son las siguientes:

a. Establece claramente cuáles son los elementos claves que deben revisarse para determinar si existen impactos sobre el medio ambiente y su significancia. Estos elementos son la existencia de extracción de recursos naturales renovables, las áreas utilizadas por las instalaciones del proyecto, las emisiones $\mathrm{y}$ el manejo de residuos $\mathrm{y}$ sustancias químicas.

b. Establece diferencias entre los impactos sobre los recursos naturales renovables y los impactos generados sobre los aspectos sociales de la evaluación.

c. Limita el número de rondas de preguntas en el caso de las DIA. El reglamento anterior establecía que podía generarse un número infinito de preguntas y respuestas $\mathrm{y}$ el nuevo reglamento limita dicha cantidad a dos rondas de

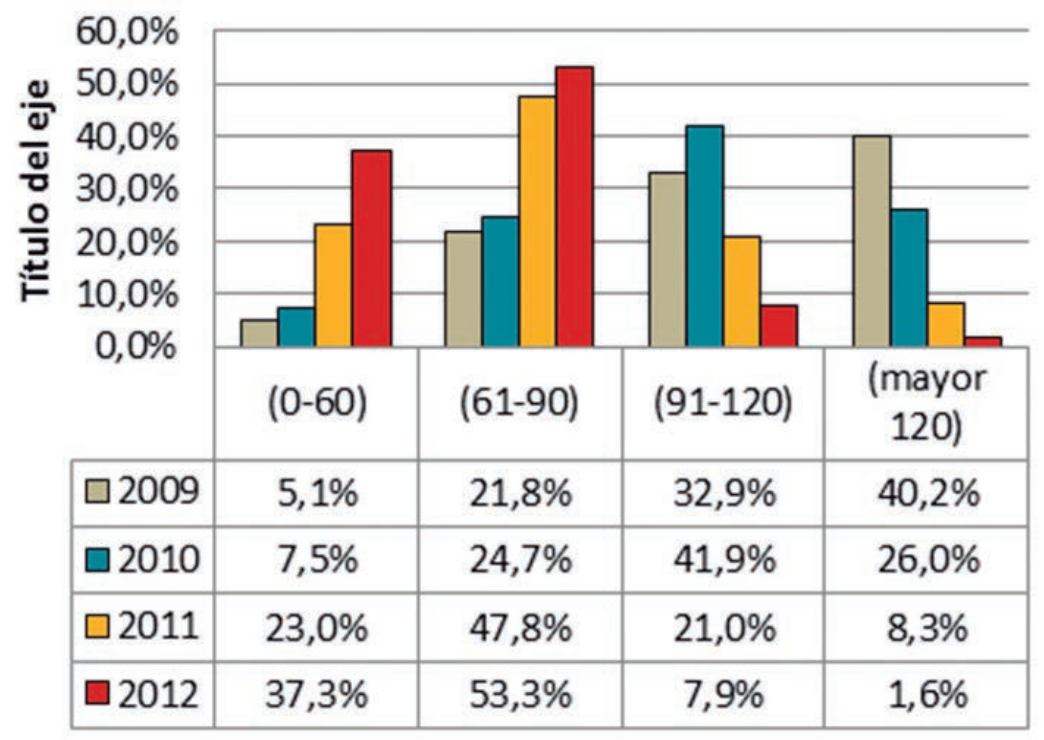

Figura 1: Días hábiles utilizados en la calificación de Declaraciones de Impacto Ambiental Fuente: Presentación “Principales Cifras Sistema de Evaluación de Impacto Ambiental 2009-2012 Enero - Junio. Gobierno de Chile 
preguntas y respuestas. Esto genera un incentivo a que se presenten mejores proyectos y evita que la autoridad continúe haciendo preguntas cuando ya se tiene identificado si existen o no impactos significativos.

2. Generación de Guías y Criterios para la evaluación: Se dotó a la autoridad ambiental (SEA) de la facultad de dictar guías técnicas referidas a la evaluación de impactos y así aportar a la certidumbre disminuyendo el margen de discrecionalidad por parte de las autoridades de servicios con competencia ambiental. Desde entonces se han venido desarrollando guías de evaluación por tipología de proyectos en que se explicitaban los aspectos claves de cada tipo de proyecto. También se desarrollaron guías orientadoras de cuándo se estaba en presencia de impactos significativos $y$, por ende, se requería la evaluación del proyecto a través de un EIA. Se realizaron también guías para describir el territorio en el que se emplaza un proyecto, para utilizar modelos adecuados de predicción al medio ambiente y para mejorar los procesos de participación ciudadana.

\section{Resultados}

¿Cómo está compuesta la reglamentación de sismoresistencia colombiana?

En relación a los resultados del trabajo realizado quisiera detenerme en dos:

El primero tiene relación con el gran desafío que tenían las Declaraciones de Impacto Ambiental. Por ser proyectos que no generan impactos significativos pareciera ser que un plazo total de 60 días (extensible a 90) es un plazo razonable para calificar proyectos. Esto, cumplir con evaluar dentro del plazo, fue uno de los objetivos y de los compromisos asumidos en la administración. La Figura 1 muestra el porcentaje de proyectos calificados durante los

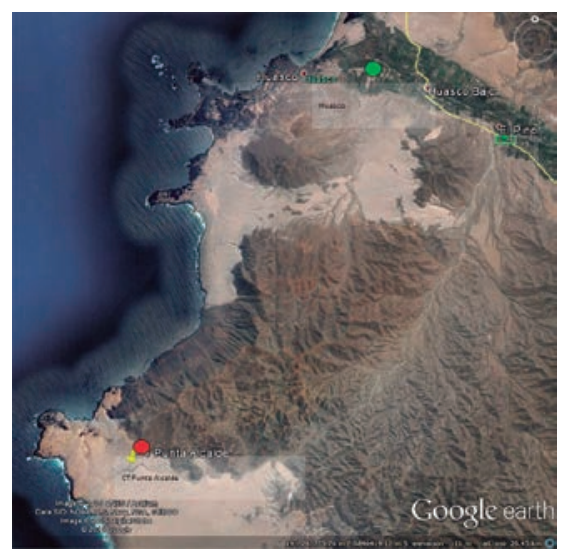

Figura 2: Ubicación de Central Térmica Punta Alcalde y localidad de Huasco Fuente: Elaboración propia

primeros 60 días, entre el día 61 y 90, entre los días 91 y 120 y finalmente los proyectos que se calificaban en más de 120 días. Como se observa en la Figura, en el 2009 se calificaban fuera de plazo el $73 \%$ de los proyectos, cifra que se disminuyó de manera continua hasta alcanzar menos del 10\% durante el 2012.

El segundo aspecto en el que quiero detenerme, a diferencia del punto anterior, tiene relación con la evaluación de los grandes proyectos de inversión y las ventajas de incorporar en la evaluación de impacto ambiental la ingeniería y la investigación en ingeniería. Lo anterior lo ilustraré con el caso de evaluación del proyecto Punta Alcalde.

El proyecto Punta Alcalde consiste en la construcción y operación de una central termoeléctrica a carbón con dos unidades de generación de aproximadamente 370 MW de generación cada una. El proyecto incorpora un muelle mecanizado para descargar carbón, canchas de acopio de carbón y piedra caliza, y un depósito para la disposición de cenizas y escorias. Consideraba como sistema de tratamiento de las emisiones atmosféricas un equipo de abatimiento de material particulado (filtro de mangas o precipitador electrostático) y un sistema de reducción de las concentraciones de NOx de selección catalítica reductiva (SCR) y un desulfurizador para reducir las concentraciones de SOx. Los gases tratados salen a la atmósfera por medio de una chimenea, de altura aproximada de 100 metros.

Junto a lo anterior se consideraba tomar un caudal aproximado de 105.000 $\mathrm{m}^{3} / \mathrm{h}$ de agua de mar para refrigeración, realizando la descarga a nivel superficial con un diferencial de $10{ }^{\circ} \mathrm{C}$.

El proyecto se localiza $15 \mathrm{Km}$ al sur de Huasco. Huasco es una localidad que presenta altos niveles de contaminantes atmosféricos debidos a distintas fuentes industriales existentes en el sector. Las concentraciones ambientales alcanzan niveles de latencia para el $\mathrm{PM}_{10}$ y concentraciones similares al nivel de saturación para el $\mathrm{PM}_{2,5}{ }^{2}$.

El proyecto fue rechazado en la Comisión de Evaluación (instancia regional) debido a que no compartió la afirmación del titular del proyecto, que a lo largo de todo el proceso de evaluación afirmó que no impactaría de manera significativa la calidad del aire ni generaría impacto significativo en el cuerpo de agua receptor debido a la descarga del agua de enfriamiento. A juicio de la Comisión de Evaluación el titular del proyecto no presentó los antecedentes que permitieran descartar la afectación a dichas componentes. A continuación analizaremos lo relacionado a la calidad del aire por ser tema de mayor significancia al impacto sobre el medio marítimo por la descarga del agua de enfriamiento.

Luego de ser calificado desfavorablemente, el titular del proyecto reclamó al Comité de Ministros para obtener la aprobación.

A esa fecha, el Servicio de Evaluación de Impacto Ambiental había desarrollado una investigación interna a los 50 proyectos energéticos principales y 50 proyectos mineros materializados principales que habían sido previamente evaluados. Las conclusiones habían sido lapidarias. En todos los proyectos anteriores los antecedentes presentados no permitían asegurar que no se generaran efectos adversos sobre la calidad del aire ya que los modelos utilizados

\footnotetext{
2 Se entiende que existe una condición de latencia cuando la calidad del componente medido -en este caso aire- está en un porcentaje de entre un $80 \%$ a $100 \%$ del máximo permitido por una norma de calidad.
} 


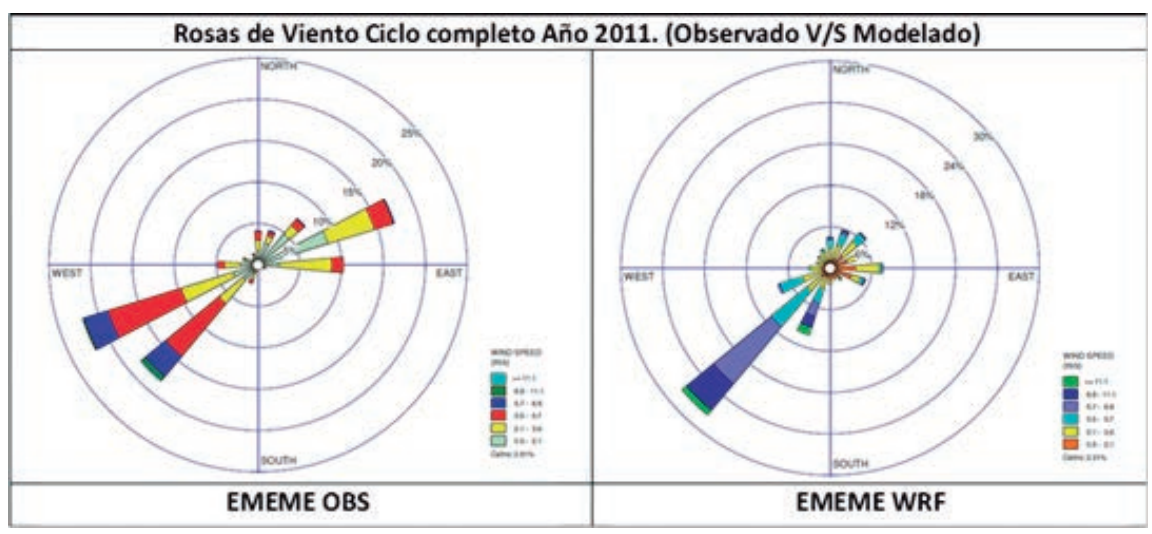

Figura 3. Rosas de Viento Ciclo completo año 2011. (ObersvadoV/S Modelado). Fuente: Servicio de Evaluación Ambiental
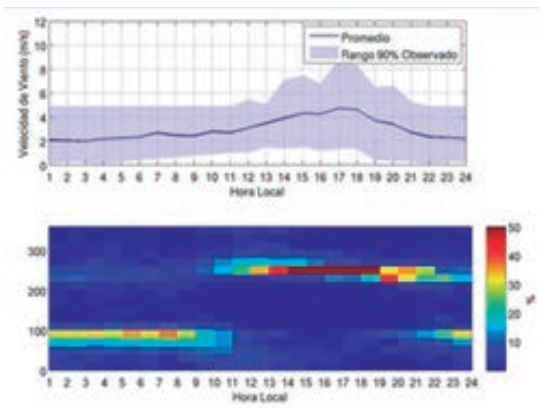

Ciclos DiarioEMEME OBS
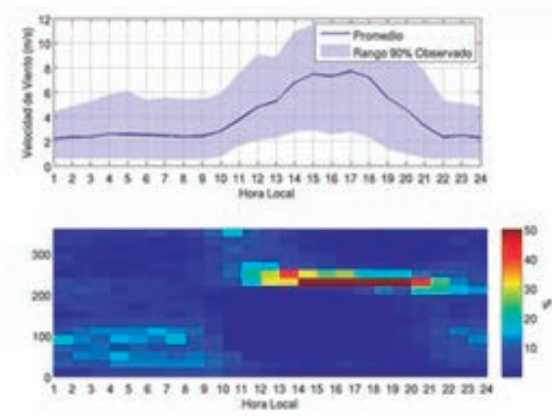

Ciclos DiarioEMEME WRF
Figura 4. Ciclos diarios de velocidad y dirección del viento (Observado V/S Modelado), Fuente: Servicio de Evaluación Ambiental
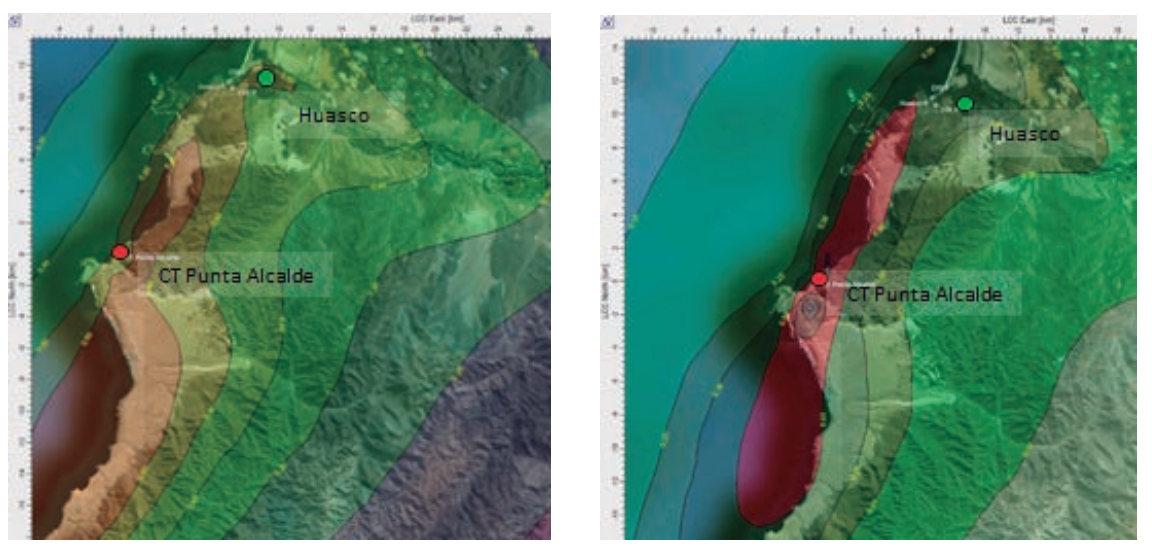

Figura 5. Curvas de Isoconcentración de PM2,5 con altura de chimenea original (100 m) y luego de medida de mitigación (150 m). Muestran que el PM2,5 emitido se dirige hacia Huasco. Fuente: Servicio de Evaluación Ambiental para predecir el impacto no presentaban la información necesaria para poder ser validados ni realizaba análisis de sensibilidad de sus resultados. Tampoco existían metodologías estandarizadas.

Junto a esa investigación, estaba en fase final de elaboración la Guía de Evaluación para el Uso de Modelos de Calidad del Aire en el SEIA, la que establecía, entre otros aspectos la necesidad de uniformar el modelo a utilizar, incorporando el modelo meteorológico Weather Research and Forecasting (WRF) con una grilla de 1x1 $\mathrm{Km}^{2}$ en vez de CALMET con una grilla de $4 \times 4 \mathrm{Km}^{2}$ que era el estándar a la fecha.

De esta manera, el Comité de Ministros se enfrentaba a un proyecto que no había presentado la información suficiente para descartar afectación al aire, pero también es cierto que la información presentada cumplía con el estándar que se exigía habitualmente a los proyectos. De esta manera podría decirse que existía cierta arbitrariedad en generar un rechazo por falencias que eran habituales a la fecha de calificación del proyecto.

Frente a tal escenario, el Comité de Ministros decide solicitar al SEA (y no al titular del proyecto) que realice una nueva modelación que cumpla el nuevo estándar e incorpore el análisis de las medidas de mitigación o compensación adecuadas al proyecto ${ }^{3}$.

Lo primero que se hizo fue un modelo al que se le realizó un análisis de incertidumbre asociado a las diferencias entre lo modelado y el comportamiento real. La Figura 4 muestra en la primera columna los valores observados y en la segunda los valores modelados en la estación meteorológica M (EMEME). En dichas figuras se puede apreciar el buen comportamiento del modelo respecto a la situación observada.

Ya habiendo construido un modelo confiable, tal como se observa en la Figura 5, se pudo concluir que el PM2,5 se dirige al valle de Huasco

\footnotetext{
3 Recordemos que la nueva institucionalidad ambiental contemplaba la posibilidad de que el Comité de Ministros pidiera informes técnicos durante el recurso de reclamación.
} 


\begin{tabular}{|c|c|c|c|c|}
\hline \multirow{2}{*}{ Estación } & \multicolumn{2}{|c|}{ Impacto con altura de $\mathbf{1 0 0} \mathbf{~}$} & \multicolumn{2}{c|}{ Impacto con altura de $\mathbf{1 5 0} \mathbf{~}$} \\
\cline { 2 - 5 } (Receptor) & PM10 Total & PM2.5 Total & PM10 Total & PM2.5 Total \\
\hline EMEM & 1,19 & 1,12 & 0,80 & 0,76 \\
\hline EMEF & 1,22 & 1,15 & 0,84 & 0,78 \\
\hline Huasco & 1,25 & 1,18 & 0,84 & 0,79 \\
\hline Huasco 2 & 1,28 & 1,20 & 1,06 & 0,99 \\
\hline
\end{tabular}

Tabla 1. Impacto de emisiones atmosféricas (ug/m3N) de CT Punta Alcalde con altura de chimenea de $100 \mathrm{~m}$ y $150 \mathrm{~m}$

Fuente: Servicio de Evaluación Ambiental

\begin{tabular}{c|c|c|c|c|}
\multirow{2}{*}{ Estación } & \multicolumn{2}{|c|}{ Impacto Fuente Existente } & \multicolumn{2}{c}{ Impacto fuente existente } \\
\cline { 2 - 5 } (Receptor) & $\begin{array}{c}\text { con sistema de } \\
\text { abatimiento }\end{array}$ & PM2.5 Total & PM10 Total & PM2.5 Total \\
\hline EMEM & 2,97 & 2,68 & 0,17 & 0,17 \\
\hline EMEF & 3,71 & 3,35 & 0,18 & 0,17 \\
\hline Huasco & 4,01 & 3,62 & 0,19 & 0,18 \\
\hline Huasco 2 & 6,23 & 5,62 & 0,23 & 0,22 \\
\hline
\end{tabular}

Tabla 2. Impacto en fuente existente sin y con precipitador electrostático Fuente: Servicio de Evaluación Ambiental

\begin{tabular}{|c|c|c|}
\hline $\begin{array}{c}\text { Estación } \\
\text { (Receptor) }\end{array}$ & PM10 Total & PM2.5 Total \\
\hline EMEM & 1,61 & 1,39 \\
\hline EMEF & 2,31 & 2,03 \\
\hline Huasco & 2,57 & 2,26 \\
\hline Huasco 2 & 4,72 & 4,20 \\
\hline
\end{tabular}

Tabla 3. Ganancia ambiental luego de implementado el proyecto con medida de compensación

generando un impacto significativo en el área de influencia del proyecto producto de sus aportes a la calidad del aire, siendo el desafío establecer una medida de mitigación o compensación adecuada para hacerse cargo de ello. Lo primero que se evaluó, como medida de mitigación, fue elevar la altura de la chimenea. Dicha medida, al aumentar las posibilidades de dispersión, efectivamente disminuye el impacto sobre la localidad de Huasco. A continuación, en la Tabla 1, se muestra el impacto en PM2,5 con la altura original de la chimenea $(100 \mathrm{~m})$ y con la altura mayor (150 m).

Sin embargo, y a pesar de la medida de mitigación, se generaba un impacto importante en una zona que tenía concentraciones similares a la saturación para PM2,5, por lo que se procedió a evaluar como medida de compensación alternativa a la medida de mitigación antes descrita, la instalación de un precipitador electrostático en una fuente distinta y ya existente en la cercanía de Huasco.

Esta medida de compensación generaba un beneficio ambiental bastante mayor al impacto generado por Punta Alcalde, lo que provocaba una ganancia ambiental neta y tenía un costo similar al aumento de la altura de la chimenea lo que en definitiva se tradujo en que se haya optado por incorporar esta exigencia ambiental al proyecto por sobre el aumento de la altura de la chimenea.

La Tabla 2 muestra el impacto de la fuente existente sin precipitador electrostático (condición original) y con precipitador electrostático (luego de instalar un precipitador electrostático).

Frente a costos económicos similares, la mejor alternativa era la exigencia de la medida de compensación. La Tabla 3 muestra la ganancia ambiental luego del desarrollo del proyecto Punta Alcalde con la medida de compensación exigida.

\section{Conclusiones}

En este artículo se ha intentado mostrar cómo el uso de la investigación y de la ingeniería en la evaluación de impacto ambiental genera aportes concretos. De la experiencia ilustrada es posible identificar:

1. Parece sumamente adecuado que en los proyectos complejos, con alta conflictividad social, existan instancias de reclamación posterior en que se pueda pedir nueva información técnica que ayude a dirimir los aspectos que sigan en conflicto. Esto permite poder identificar y corregir, en caso de ser necesario, aspectos que puedan haber quedado sin solución en la instancia de evaluación de impacto ambiental. En esta instancia se deben hacer todos los esfuerzos por tener informes independientes de alto nivel técnico y alta credibilidad pública, lo que genera una gran oportunidad para la investigación y la ingeniería.

2. Junto a lo anterior, se observa un gran espacio para la participación de la investigación y la ingeniería en la generación de criterios, guías y directrices, lo que en definitiva permite disminuir la discrecionalidad política y técnica de la evaluación de impacto ambiental. Lo anterior puede contribuir también a una 
disminución significativa de los plazos de evaluación de impacto de proyectos, muy especialmente en proyectos de bajo impacto y baja conflictividad social.

3. En relación a los proyectos complejos y de alta complejidad social, se observa que la utilización de modelos matemáticos adecuados, así como la generación de información independiente se puede transformar en una herramienta potente que garantice el cuidado del medio ambiente $y$, al mismo tiempo, permita viabili- zar proyectos de inversión.

4. Es importante destacar que la información técnica de alto nivel dota de una gran certidumbre al proceso de evaluación, lo que disminuye la posibilidad de utilizar el principio precautorio como fundamento para rechazar un proyecto.

5. Naturalmente que lo anterior sólo es posible si se cuenta con una autoridad ambiental empoderada y que cuente con los recursos técnicos, económicos y humanos para generar informa- ción de alto nivel.

\section{REFERENCIAS}

Morrison-Saunders, A. \& Sadler, B. (2010). The art and science of impact assessment: results of a survey of IAIA members. Impact Assessment and Project Appraisal, 28(1), 77-82.

Servicio de Evaluación Ambiental. Gobierno de Chile. http://www.sea. gob.cl/contenido/guias-para-laevaluacion-de-impacto-ambiental 